\title{
Arteriovenous Fistula Involving the Inferior Petroclival Vein -Case Report-
}

\author{
Yasushi SUGIURA ${ }^{1}$ and Shigeru NISHIZAWA ${ }^{2}$ \\ ${ }^{1}$ Department of Endovascular Neurosurgery, Seirei Mikatahara Hospital, Hamamatsu, Shizuoka; \\ ${ }^{2}$ Department of Neurosurgery, University of Occupational and \\ Environmental Health, Kitakyushu, Fukuoka
}

\begin{abstract}
A 68-year-old man presented with an extremely rare extracranial arteriovenous fistula (AVF) involving the inferior petroclival vein (IPCV) with retrograde venous drainage into an ophthalmic vein through the anterior condylar confluence and inferior petrosal sinus manifesting as ocular symptoms. The AVF was successfully treated by selective transvenous embolization with platinum coils. AVF involving the IPCV should be recognized as a possible extracranial lesion manifesting as clinical symptoms similar to cavernous sinus dural AVF.
\end{abstract}

Key words: inferior petroclival vein, arteriovenous fistula, ocular symptom, cavernous sinus, embolization

\section{Introduction}

The anatomical or clinical importance of an inferior petroclival or petrooccipital vein, which courses along the extracranial surface of the petroclival or petrooccipital fissure, is rarely discussed, ${ }^{2,3)}$ and vascular lesions involving the inferior petroclival vein (IPCV) have not been reported. We treated a patient with an arteriovenous fistula (AVF) involving the IPCV manifesting as ocular symptoms. The clinical symptoms were very similar to those of cavernous sinus dural AVF, so the existence of such a very rare lesion, the mechanisms causing the clinical symptoms, and the differential diagnosis from cavernous sinus dural AVFs are important to recognize.

\section{Case Report}

A 68-year-old man noticed left pulsatile tinnitus persisting for 9 months. The patient developed left conjunctival injection 4 months before admission. Physical examination found conjunctival injection and chemosis of the left eye. Pulsatile bruit was audible over the left mastoid process. Cerebral angiography showed an AVF located in front of the upper portion of the left inferior petrosal sinus (IPS) and adjacent to the left foramen lacerum (Fig. 1). The AVF mimicked a dural arteriovenous shunt, with blood supply from branches of the bilateral ascending pharyngeal arteries, the inferolateral trunk, and the artery of the foramen lacerum (Fig. 1). Arterial supply from the posterior ascending artery originating from the left vertebral artery

Received April 6, 2010; Accepted May 28, 2010 was also seen. Right external carotid angiography clearly demonstrated the fistulous venous pouch (Fig. 1D). The AVF drained through the left anterior condylar confluence (ACC) into the left internal jugular vein, the an-

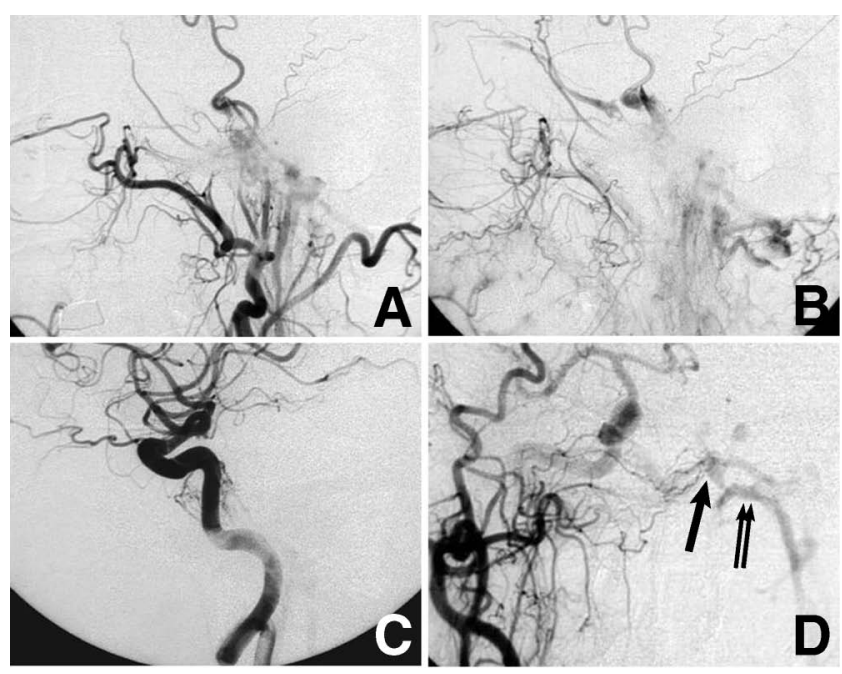

Fig. 1 A, B: Left external carotid angiograms, lateral views, showing an arteriovenous fistula with retrograde venous drainage into the left superior ophthalmic vein. C: Left internal carotid angiogram, lateral view, showing arterial supply from the inferolateral trunk and the artery of the foramen lacerum. D: Right external carotid angiogram, anteroposterior view, showing the fistulous pouch (arrow). Double arrow: anterior condylar confluence. 


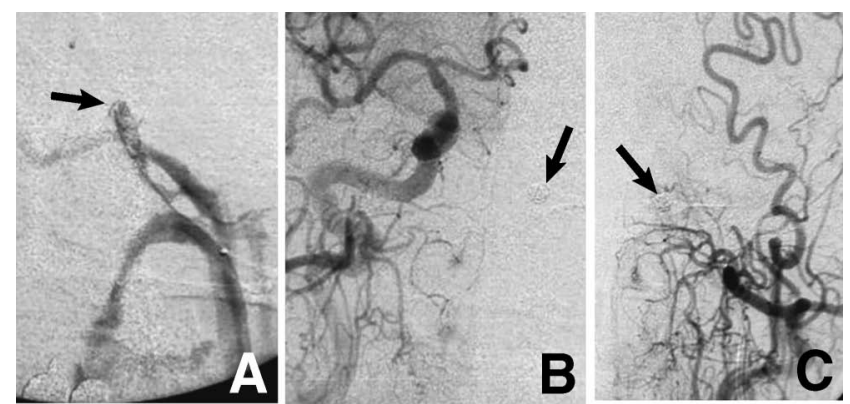

Fig. 2 A: Venogram during embolization, anteroposterior view, showing the fistulous pouch (arrow). B, C: Right (B) and left (C) external carotid angiograms immediately after embolization, anteroposterior views, showing no contrast filling of the arteriovenous fistula. Arrow: coil mass.
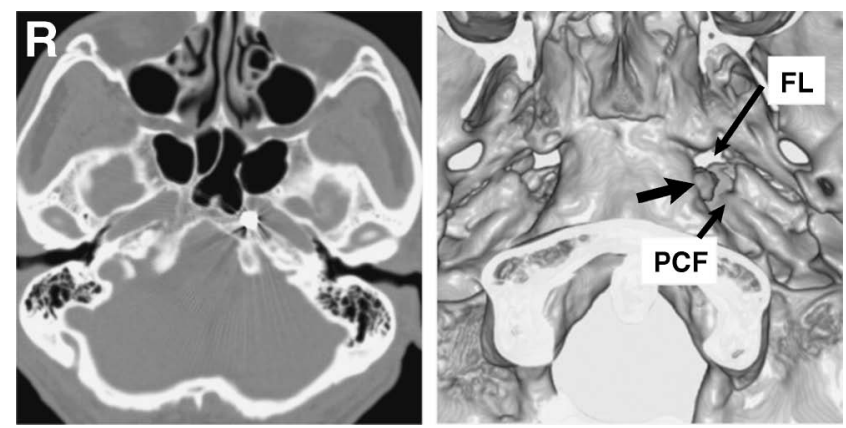

Fig. 3 Left: Axial computed tomography bone window image after embolization showing the coil mass medial to the left carotid canal. Right: Three-dimensional computed tomography scan, axial view, showing the coil mass (arrow) in the left petroclival fissure (PCF). FL: foramen lacerum.

terior condylar vein, and the left IPS (Fig. 1). Retrograde venous drainage into the left IPS continued to the left cavernous sinus and the superior ophthalmic vein (Fig. 1B). Venous drainage through the basilar venous plexus into the right internal jugular vein was also seen.

The patient underwent transfemoral transvenous embolization of the AVF under local anesthesia. The tip of a 5-French SGUR guiding catheter (Cook Medical, Bloomington, Indiana, USA) was placed in the left internal jugular vein. An Excelsior microcatheter (Boston Scientific, Natick, Massachusetts, USA) was navigated through the ACC to the affected fistulous pouch with a 0.016 -inch GT guidewire (Terumo, Tokyo) (Fig. 2A). The venous pouch was selectively packed using two Guglielmi detachable coils (GDCs), GDC10 $4 \mathrm{~mm} \times 10 \mathrm{~cm}$ and $3 \mathrm{~mm} \times 12 \mathrm{~cm}$ (Boston Scientific). Angiography performed immediately after embolization showed no contrast filling of the AVF (Fig. 2B, C).

Bruit disappeared immediately after embolization, and ocular symptoms resolved within a few days. Computed tomography (CT) performed 8 years after the treatment showed the coil mass at the inferior surface of the left petroclival fissure just inferomedial to the left foramen
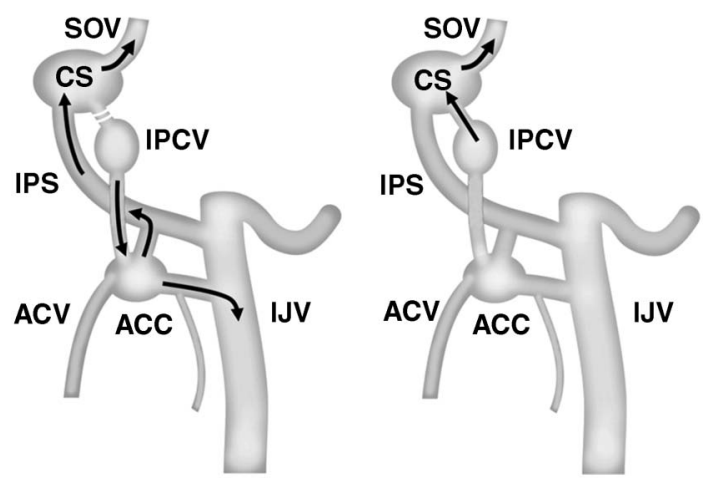

Fig. 4 Schema showing the venous drainage route in the present case (left) and a possible drainage route (right) of an arteriovenous fistula involving the inferior petroclival vein (IPCV). ACC: anterior condylar confluence, ACV: anterior condylar vein, CS: cavernous sinus, IJV: internal jugular vein, IPS: inferior petrosal sinus, SOV: superior ophthalmic vein.

lacerum (Fig. 3).

\section{Discussion}

The petroclival or petrooccipital fissure is located between the lateral edge of the clivus and the petrous part of the temporal bone. The anterior and posterior ends of the fissure are the foramen lacerum and jugular foramen, respectively. The IPCV courses along the extracranial or inferior surface of the petroclival fissure and is a mirror image of the IPS, which courses along the intracranial or superior surface of the fissure. ${ }^{2,3)}$ Angiographic and CT findings in the present case indicated that the AVF was located at the left IPCV.

AVF involving the IPCV has not been reported previously. The IPCV communicates with the ACC caudally and the cavernous sinus through the internal carotid artery venous plexus cranially. ${ }^{2,3,6)}$ Therefore, if an AVF occurs at the IPCV, both may form drainage routes. In the present case, the venous drainage descended into the ACC only (Fig. 4 left). This retrograde venous drainage into the IPS, cavernous sinus, and ophthalmic vein via the ACC resulted in the ocular symptoms. An ACC is located extracranially in front of the aperture of the hypoglossal canal. ${ }^{6}$ ) Tributaries of this venous confluence are the internal jugular vein, lateral and anterior condylar veins, IPS, prevertebral venous plexus, and IPCV. ${ }^{6}$ ) The ACC may be clinically significant in dural AVFs of the anterior condylar vein or hypoglossal canal. Some patients with these lesions presented with ocular symptoms similar to cavernous sinus dural AVFs due to the retrograde venous drainage into the IPS, cavernous sinus, and ophthalmic vein, ${ }^{1,5,9)}$ and attributed to the anatomical communication of the ACC and IPS. Although the IPCV is a minor tributary of the ACC, the AVF involving this vein should be recognized as a possible cause of ocular symptoms similar to cavernous sinus dural AVFs.

If the AVF involving the IPCV primarily drains into the cavernous sinus, in contrast to the present case, the angio- 
graphic findings of the lesion may mimic those of cavernous sinus dural AVF (Fig. 4 right). Fistulous portions of cavernous sinus dural AVFs outside the sinus are not exceptional, ${ }^{7)}$ so that some lesions such as dural AVFs involving the basilar venous plexus can be confused with cavernous sinus dural AVFs. ${ }^{8)}$ AVF involving the IPCV with primary venous drainage into the cavernous sinus may be similarly misdiagnosed as cavernous sinus dural AVF. Although the presentation spectrum is continuous with cavernous sinus dural AVFs, AVF involving the IPCV deserves its own category because of the extracranial location. Therefore, the presence of AVF involving the IPCV should be considered if angiography detects a fistulous portion of an AVF around the cavernous sinus adjacent to a foramen lacerum.

Transvenous embolization is extremely effective for the treatment of dural AVFs involving some locations such as the cavernous sinus. ${ }^{4)}$ Contralateral carotid angiography is useful for localizing the fistulous portion and achieving selective transvenous embolization of AVFs involving an anterior condylar vein or hypoglossal canal.1,5) In the present case, contralateral carotid angiography also clearly demonstrated the fistulous pouch, and the AVF could be occluded by placement of a small number of platinum coils. Selective transvenous embolization may be a safe and effective treatment for AVF involving the IPCV.

\section{References}

1) Ernst R, Bulas R, Tomsick T, van Loveren H, Aziz KA: Three cases of dural arteriovenous fistula of the anterior condylar vein within the hypoglossal canal. AJNR Am J Neuroradiol 20: 2016-2020, 1999

2) Katsuta T, Matsushima T, Uda K: [Surgical anatomy of the skullbase venous system: petroclival region]. No Shinkei Geka Journal 17: 738-744, 2008 (Japanese)

3) Katsuta T, Rhoton AL, Matsushima T: The jugular foramen: microsurgical anatomy and operative approaches. Neurosurgery 41: 149-202, 1997

4) Kirsch M, Henkes H, Liebig T, Weber W, Esser J, Golik S, Kuhne D: Endovascular management of dural carotid-cavernous sinus fistulas in 141 patient. Neuroradiology 48: 486-490, 2006

5) Kiyosue H, Tanoue S, Okahara M, Mori M, Mori H: Ocular symptoms associated with a dural arteriovenous fistula involving the hypoglossal canal: selective transvenous coil embolization. Case report. J Neurosurg 94: 630-632, 2001

6) San Millan Ruiz D, Gailloud P, Rufenacht DA, Delavelle J, Henry F, Fasel JH: The craniocervical venous system in relation to cerebral venous drainage. AJNR Am J Neuroradiol 23: 1500-1508, 2002

7) Satow T, Murao K, Okawa M, Nishida T, Masuda K, Miyamoto S: [Neuroendovascular therapy for cavernous sinus dural arteriovenous fistulas based on functional angiology]. No Shinkei Geka Journal 17: 679-689, 2008 (Japanese)

8) Shi ZS, Ziegler J, Gonzalez NR, Feng L, Tateshima S, Jahan R, Duckwiller G, Vinuela F: Transarterial embolization of clival dural arteriovenous fistula using liquid embolic agents. Neurosurgery 62: 408-415, 2008

9) Tanoue S, Goto K, Oota S: Endovascular treatment for dural arteriovenous fistula of the anterior condylar vein with unusual venous drainage: report of two cases. AJNR Am J Neuroradiol 26: 1955-1959, 2005

Address reprint requests to: Yasushi Sugiura, MD, Department of Endovascular Neurosurgery, Seirei Mikatahara Hospital, 3453 Mikatabara-cho, Kita-ku, Hamamatsu, Shizuoka 433-8558, Japan. e-mail: sgur-y@sis.seirei.or.jp 